\title{
Vulnerability Index - application and suitability of different methodologies applied to the municipality of Cuiabá, Mato Grosso - Brazil
}

\author{
Gabrielly Silva $^{1, a}$, Marcelo Miguez ${ }^{1}$, Leandro Di Gregório² and Aline Veról ${ }^{3}$ \\ ${ }^{1}$ Av. Athos da Silveira Ramos, 149, CT, bloco I, sala I206, Cidade Universitária, Rio de Janeiro 21941-909, Brazil \\ ${ }^{2}$ Av. Athos da Silveira Ramos, 149, CT, bloco D, sala D207, Cidade Universitária, Rio de Janeiro 21941-909, Brazil \\ ${ }^{3}$ Av. Pedro Calmon, 550, sala 422, Prédio da Reitoria/FAU, Cidade Universitária, Rio de Janeiro 21941-901, Brazil
}

\begin{abstract}
Urbanization is an increasingly fast process nowadays especially, in some Asian regions and Latin America. Cuiabá - the main city of Mato Grosso, state in the Midwest of Brazil - is a city with current population of 580,000 inhabitants, and an urbanization rate of $98 \%$. Frequently, in Brazil, flood risk management still focuses on structural measures intending to diminish flood levels. However, prior to the adoption of these measures it is important to assess and map the existing vulnerabilities to guide decision makers on the choice of a coherent set of the technologies to be applied. This work proposes to apply four methodologies for determining the various aspects of urban vulnerability in the fully urbanized catchment of Cuiabá. Each chosen methodology sought to determine a specific aspect of vulnerability: social, economic, structural and environmental. A premise of this study considered the need of replicating these methodologies based on data freely available by the National Census. After calculations were carried out, the results were spacialized, by GIS tools and cross-sectional analysis was made to assess the vulnerability. The lessons learned showed the fragilities of the city in order to improve the process of flood risk management.
\end{abstract}

\section{Introduction}

The floods are results from a natural process; however, the urban development has the potential to generate negative impacts, because some of its consequences are the increase of impermeable areas and larger production of waste and sediment. Therefore, there is an increase of flow rate, contamination and partial contamination of the macro drainage system and, sometimes, the insufficiency or inefficiency of that system. That way, a natural phenomenon can transform into a "natural disaster". However, it is actually the anthropic action that enhances the negative results generated from the natural phenomenon, creating damage in the environment, turning it into a disaster.

An increase in urbanization is very noticiable nowadays, the process being elevate in some regions with the most recent development, especially in Asia and Latin America. For example, in Brazil there are already 12 capitals where the population is over 1 million (IBGE*, 2010). Amongst the highly urbanized capitals, some of them have been facing problems associated with uncontrolled urbanization and without due caution when managing rain waters, making it possible to highligh difficulties in every one of those capitals. The increase in the number of floods with poisonous impacts observed recently in Brazil has been progressively interesting several departments of society for ways that can predic

\footnotetext{
a Corresponding author: gabrielly@coc.ufrj.br
}

such events, reducing the impacts and also preparing both the society and the city and live in the more resilient manner with that reality.

The solutions (preventive or mitigating) to the flood problem don't restric to the structural measures. The appropriate planning for soil usage, the controlled and concious urbanization, the appropriate handling of water bodies and the population education allow for good results in flood and overflow with loss shrinkage (World Bank, 2012). However, after the adoption and implementation of the preventive measures, it is necessary to identify the regions where interventions are needed to reduce the already existing risks, the study being accomplished based on vulnerability analysis, associated to the comprehension of the space-time dynamic of danger.

Until now, there's no unanimity in relation to equating the concept of vulnerability. This study work with the concepts of vulnerability inherent to risks of hydrological disasters, analyzing its sections: environmental, structural, social and economic. From the evaluation of existing methodologies covering those sections, these different conceptions are applied to a Brazilian state capital, for the identification of the adequacy and the necessity of adaptation to the new reality, different from the original methodology. 


\section{Questioning of the study area - The city of Cuiabá/Brazil}

Cuiabá is the capital of the state of Mato Grosso. The city has a define rainfall regimen, with a dry period from 4 to 6 months (May to October), and another one rainy where rainfall with elevated intensity and short duration concentrate (SEPLAN, 2009). The city has a population of around 550.000, and an urbanization rate of 98\% (IBGE, 2010). Similar to other cities, the urbanization process occured in a disordely fashion (especially from the year 1960 to 1980) in relation to the legal instruments of soil planning.

Its been defined as the focal point of the study the catchment of the Barbado stream, that is approximately $12 \mathrm{~km}^{2}$. The main body of water around $9 \mathrm{~km}$ long, crossing through 25 neighborhoods, as seen on Figure 1 (CUIABÁ, 2009). In its superior strech, the catchment still has a low level of anthropization; however, from its mid course to inferior course, it has been pratically all modified. In its area are localized important community equipaments: the State's Political and Administrative Center, a Federal Education Institute of Mato Grosso campus, the Federal University of Mato Grosso campus, in addition to the roads that link the city. In the last few years, the catchment has been suffering several interventions from engineering construction work (plumbing and corrections), increasing the potential of transferance from floods to downstream.

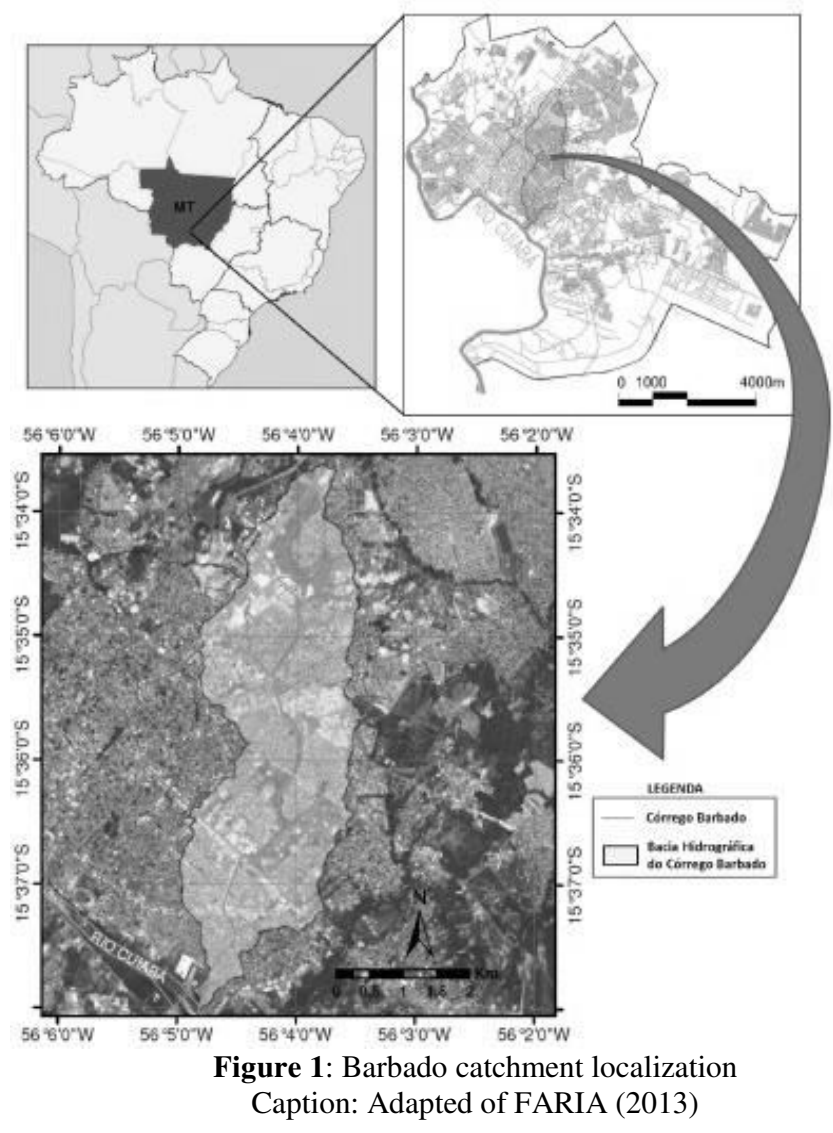

Regarding the urban planning in Cuiabá, the city has its Master Plan approved by Municipal Law $\mathrm{n}^{\circ}$ 150/2007 where guidelines are dictated for the management of the urban drainage system and recomendation to the Sanitation Plan preparation. In 2011 and 2014, respectively, were approved the Municipal Plans of Water and Sewer and of Solid Waste; however the Urban Drainage Plan is still under construction. Highlighting that, according to the Brazilian Sanitation Law, from 2007, the activities of treatment and supply of water, collection and treatment of sewer, solid waste and urban drainage should be inseparable. As an auxiliary tool for managing the urban drainage system there is the Law of Use, Occupation and Urbanization of Soil $\mathrm{n}^{\circ}$ $389 / 2015$.

Several authors studied the environmental problem at the Barbado strem catchment. According to Carvalho (2013), it was verified the interference produced by the insertion of Parque Barbado Avenue (by the mid-inferior course of the stream). It was realized a flood simulation using the SWMM tool with return time (RT) from 50 to 100 years, where there were detected floods in both RT with potential to cause damage to the avenues structure as well as the drainage system, especially downstream of the catchment.

Zorzo (2015) developed a study with the goal of listing the conditioning factors to generating floods in the area, analyzing the interference of urbanization, zoning, topographic characteristics, and maping with records of the sewer grates along the watershed. The main factors were: failure in the micro-drainage system, added to the absence of maintenence and cleaning of the sewer grates, as well as inadequate urbanization of areas that are environmentally sensible. This picture portrays the association between the failure in the urbanization process and the inadequate treatment of waste, causing problems to the watershed drainage system. Other studies focusing on understanding the drainage system and environmental processes (VENTURA, 2011; FARIA 2013; ROTHERBARTH et al, 2013) also indicate that importance.

Facing this scenario, this study's proposal is to assist the process of flood risk management in the Barbado stream catchment, in Cuiabá. From understanding the risk as being a set of components (threat, vulnerability, exposure and resilience), it's necessary to seek to focus on the vulnerability aspect, which is the component resulting directly of an urban planning that is fragile and inadequate.

\section{Objectives}

\subsection{General}

To apply different methodologies to determine the vulnerability (structural, social, environmental and economic) in the Barbado stream urban catchment in 
Cuiabá, and analyze the results, seeking to evaluate the usage potential, and compatibility of individual tools to the study area, with the goal of subsidize the urban planning and flood risk management.

\subsection{Specifics}

- Calculate the indexes that explicit the vulnerabilities: Structural: FRI (Zonensein, 2007), Social: SVI (Koks et al, 2014), Environmental: SEnVI (Saito, 2011) and Economic: SEcVI (Eidsvg et al, 2014);

- Spacialize the indexes determined through discretized maps on the territoiral unit of census sectors (unit that was proposed by IBGE);

- Evaluate the response specificity of each index and seek its adequacy to the Barbado stream watershed flook risk management.

The original contribution that this work aims is to promote technical and methodological basis for building a risk management policy of flooding in the city of Cuiabá, through the pursuit of replicability evaluation indexes of urban vulnerability. Therefore, it is necessary to understand the transversality of urban vulnerability in its various aspects. And as a next step in this journey, it is also proposed to establish a new composed index that seeks to cover these information gathered separately in the index already worked.

\section{Literature review}

\subsection{General concepts of vulnerability}

Vulnerability can be understood as the conditions determined by physics, economic, social and environmental factors that increase the liability of a community to the threat impacts (UNDP, 2004). To Castro (2005), vulnerability can be described as: 1 Essential condition to the body or receptor system, that in interaction with the magnitude of the event or accident, characterizes the adverse effects measured in terms of intensity of probable damage. 2 - Probability of a certain community or area being affected by a threat or potential risk for disaster, established from technical studies.

Another thread of analysis in vulnerability, developed especially inside geography, arises from studies about natural disasters and risk evaluation. In this perspective, vulnerability can be seen as being the interaction between the danger in a certain place, and the characteristics and exposure rate of its population (CUTTER, 1996). To O'Riordan (2002), vulnerability to natural disasters is given by the inability of a person or population group to avoid the danger related to natural disasters, or being forced to live in dangerous situations. Such situations occur from economic, social, environmental and political processes.

Cardona (2004) also proposes thinking of vulnerability to natural disasters in an embracing perspective, identifying three main elements in its composition: fragility or exposure;susceptibility; and lack of resilience. Fragility or exposure is the structural and environmental component of vulnerability, that captures in what way a population group is liable to be affected by a dangerous phenomenon based on its location in the area of influence, due to the lack of structural resistance to its propagation. Susceptibility is the socioeconomic and demographic component, that captures the predisposition of a population group to be damaged when facing a dangerous phenomenon; it depends on the marginality rate, social segregation and economic fragility to which the population group is subjected. Lack of resilience is the behavioral, communal and political components, that capture the ability of a population group subjected to a dangerous phenomenon to absorb the shock and adapt to move back to a acceptable state.

Birkman (2005) assures that there are five different approaches to this concept. The first considers an intern factor of the risk concept; the second one analyzes vulnerability as a probability to suffer damage; the third one is guided by a dualistic vision between susceptibility and responsiveness; the fourth one is related to a multiple structure (considering susceptibility, exposure, abillity and adaptation); the fifth approach to vulnerability presents a multidimensional character addresing structural, social, economic, environmental and institutional features.

Given the complexity of the different dimensions of vulnerability, measuring them requires the integration of a large number of information related to several subjects and knowledge areas. Working the richness of that information in a consistent manner requires the production of clear and synthetic indicators. Those indicators can work on different levels of evaluation whether they are global, national, subnational or local/sectorial. For evaluation of vulnerability in its different aspects, on a local level, the methodologies are usually developed by groups of college students and/or municipal/state institutions with views to a better understanding of urban dynamics, analysis and proposition of adjustments to planning and urban management.

To determine the different aspects of vulnerability associated urbanized areas were selected in this study four different methodologies, seeking to represent the components: environmental, social, economic and infrastructural of the urban vulnerability; each selected methodology is focused on a different characteristic to be assessed. Were chosen two methodologies developed by Brazilian researches and two other by international research groups, which are presented below

\section{FRI - Flood Risk Index}

The Flood Risk Index (FRI) consists of a methodology of a flood risk multicriteria analysis, that considers not only the flood's specificities, but also the socioeconomic characteristics of the affected population and area, information combined in a quantitative index variable from 0 to 100 where regions with low risk of flooding present reduced numbers of FRI, and more 
critical regions present higher index numbers. (ZONENSEIN, 2007).

The general formula is given by:

$$
\begin{aligned}
F R I= & \underbrace{(\underbrace{\left.\sum_{1}^{n} I_{i}^{I P} * p_{i}^{I P}\right)}_{i=l}}_{\mathrm{IP}})^{q I P} * \underbrace{\left(\sum_{j=l}^{m} I_{j}^{C} * p_{j}^{C}\right)^{q C}}_{\mathrm{C}} \\
0 & \leq p_{i}^{I P} ; p_{j}^{C} \leq 1 ; \sum_{i=l}^{n} p_{i}^{I P}=1 ; \sum_{j=l}^{m} p_{j}^{C}=1 \\
& 0 \leq p_{i}^{I P} ; q^{C} \leq 1 e q^{I P}+q^{C}=1
\end{aligned}
$$

Where

FRI: Flood Risk Index variable from 0 to 100 (higher and lower risk);

IP: Flood's specificities subindex also variable from 0 to 100

C: Consequences subindex variable from 0 to 100 .

As stated, the FRI is composed by two subindexes, and those are composed by several indicators shorty resumed next:

$\checkmark$ The IP subindex gathers the indicators that inform the main characteristics related to floods: the overflow blade, the speed factor, that is a product between the blade and the flow speed and represents flow's destructive capacity; and the permanence factor, that defines overflow permanence periods above certain water blades, setting disturbances to pedestrians, traffic and constructions.

$\checkmark$ The $\mathrm{C}$ subindex lists the indicators that affect vulnerability and exposure, increase the damage severity: households density (HD), income (I), traffic (T) and inadequate sanitation (IS). It stands out that Income here is not measurement of social susceptibility, but as an indicator of lost value, related to construction and infrastructure. Therefore, the biggest concern falls on the structural bias.

\section{SVI - Social Vulnerability Index}

A study realized by the Amsterdam University's Environmental Institute, in the Netherlands, decide to investigate the combination of social vulnerability, the danger and exposure to floods in a certain area, with the objective to promote lessons and improvements to the flood risk management (KOKS et al, 2014).

For the Social Vulnerability Index (SVI) creation two database were used: PC6 (consists in an area that covers about 20 addresses), and the avaliable data are: total population, number of one parent families, noneuropean migrants, younger than 14 years of age, older than 65 years of age, total number of families, monthly average income, propriety construction average age; and also the Adresses and Building Register, that contains data from geographic coordinates, addresses, propriety area, function and year of propriety construction.

The SVI was built based on the methodology developed by Cutter et al (2000) and modified by Wu et al (2002). For each variable analyzed a vulnerability index was created for each PC6 area, and a composed index was developed, where every index calculated for every variable were combined. To determine the PC6 general index, the variable must be normalized before being combined. To define the vulnerability index for each studied variable, it was worked the ratio between number of the variable on each PC6 (V6) and the maximum number of the variable in the study area, according to the equations.

$$
I C=\frac{V 6}{V R} \quad I C=1-\frac{V 6}{V R}
$$

For the home construction year and the monthly average income, it is presumed that the more recent the construction and the higher the income, the vulnerability index would be a lower number. That way, the SVI will vary between 0 and 1 , where numbers close to 1 denote more social vulnerability.

\section{SEnVI - Socio-environmental Vulnerability Index}

Over the development process of his doctorate thesis, Saito (2011) proposed a methodology for the determination of the socio-environmental vulnerability of low-income communities in Florianópolis. In that study he adopted as socio-environmental vulnerability the quality of the population that is exposed to processes of the structural environment (such as landslides and falling rocks) with low responsiveness and high physical exposure. Therefore, he seeked to integrate social and environmental dimensions to determine vulnerable territory.

The analysis was accomplished using two main components: the first one delimits the physical exposure to which the residents are submitted, being the analysis of this aspect realized under the infrastructure and access to services point of view; the second component is the residents' responsiveness, characterized by the social aspects that envelop the population. Therefore, from both components' results, the communities' vulnerability was analyzed. For the research's development, they use data from the CADUNICO - register used by the Brazilian Federal Government for identification and socioeconomic characterization of families that earn half of minimum wage per person, or family income of three times the minimun wage.

The residents physical exposure considers the following aspects: constructive type, public lightining, water supply, sewage, garbage collection, home ownership and home characteristics. The population responsiveness when facing threats evaluates: age, education, marital status, race, job market situation, number of residents in the house and time in the house. It was applied the HAP - Hierarchical Analysis Process (Saaty, 2005) technique to the tiering of physical exposure, residents' exposure and the communities' socioenvironmental vulnerability. Three tracks of representative rating (high, medium, low) were selected, defined by the indexes values standard deviation calculation. 


\section{SEcVI - Socio-economic Vulnerability Index}

Eidsvig et al. (2014) present a model to evaluate the socioeconomic vulnerability in relation to the landslides on a regional scale. The model is made of indicators representing the factors that influence a community's ability to prepare itself, treat and recuperate from damage and loss associated to landslides. It includes indicators that charactherize the demographic group, social and economic scenario, preparedness, response efficacy and recoverability. The vulnerability is classified on a relative scale from 1 to 5 , where 1 corresponds the lowest vulnerability and 5 corresponds the highest vulnerability; the indicators selected in the model proposed were:

-Vulnerable elements: Younger than 5 years of age and older than 65 years of age; people with language and cultural barriers; rural population that depend on natural resources as its main source of income; population density; people without post-secondary education; housing type and critical infrastructure;

-Preparation and response: The population risk perception; the capacity to quickly alert the society; the severity on regulation control and the extension of emergency protocol; the emergency response;

- Recovey: Personal wealth; existence of insurance or disasters funds; quality of medical service.

A deliberation system was introduced to explain the relative importance of each indicator to the total index. It is explained as:

- Bigger influence: Housing type, early warning capability and critical infrastructure;

- Moderate influence: Age distribution, rural population that depend on natural resources as its main source of income, personal wealth, insurance and disasters funds, risk awareness, regulation control and emergency response.

- Minor influence: Population density, vulnerable groups due to cultural barriers, education level and quality of medical service.

There was a distribution of the correspondent vulnerability scores to each indicator studied. After that assignment, the score for each indicator is multiplied by its correspondent weight, and added to give a weighted vulnerability value. The final estimate of the added vulnerability value is formulated according to the following equation:

$$
\sum_{\text {ALL INDICATORS }} \text { INDICATOR SCORE *INDICATOR WEIGHT/ } \sum \text { WEIGHTS }
$$

\section{Methodology}

Based on the border of the Barbado stream catchment, and with the assistance of a GIS tool, it was possible to define the census sectors belonging to that watershed (93 sectors). Following that step, it was possible to select the necessary data to built the census sectors database (IBGE, 2010) to Mato Grosso state. As a computer tool to built the indexes Microsoft Excel was used, and lastly, the indexes were spacialized on maps built over a shape base of census sectors of Mato Grosso, available on the IBGE website. Following that step, there were analysis and notes about the studied indexes, described in the subsequent item.

\section{FRI}

The FRI consequences subindex was worked, because it seeks to evaluate the vulnerability of an urban system (descarding the subindex that characterizes the flood). It was necessary the gathering of information: home density, income and inadequate sanitation; obtained in a simple manner in the geographic unit of census sector (minor geographic discretization avaliable by the Brazilian Institute of Geographic and Statistic - IBGE) for the year 2010; the traffic data are represented by the road tiering on the city of Cuiabá and can be obtained in the Socioeconomic Profile of Cuiabá (2009).

\section{SVI}

To determine this index, the information were gathered from the census sector database from the 2010 IBGE census. They used data from socioeconomic status, age (younger than 14 years of age and older than 65 years of age), one parent families, and an approximate property construction age (based on the neighborhood foundation year). The non-european migrants index was not calculated, because of its inadequacy to Brazilian reality.

\section{SEnVI}

The information were gathered from the census sector database from the 2010 IBGE census were also used. The data utilized were: public lightning, water supply, sewage, garbage collection, and home ownership for the variable of physical exposure; for the variable of responsiveness the data utilized were: age, education, marital status, number of people, race. The rest of the variables weren't evaluated because they are not available through IBGE.

\section{SEcVI}

Inside of the range of indicators used in the original index, were selected the ones liable of being recalculated with the Brazilian database and that could be adapted to the vulnerability when facing the urban flood process. The indicators used were: age distribution (younger than 5 years of age and older than 65 years of age), population density, education (literate or not), household income, people responsible for the household income, residence type (house, village house, apartment). Some of those indicators were adapted to the country's reality, such as: education (the original index works with the population that have college degrees, while this article works with whether the population is literate or not), people responsible for the household income (replacing the indicators of people that depend of natural resources as main source of income), and residence type (representing the housing type). 


\section{Discussion of results}

The results are presented for each of the evaluated indexes, totalizing the methodological specificities inherent to each one, as well as the relative notes. The indexes were spacialized on vulnerability maps that have the 2010 IBGE census sectors area per each geographic unit.

\section{FRI}

The results from each indicator that make up the Consequences subindex are exposed next, and lastly, a conjugate map that demonstrates the vulnerability of a urban system infrastructure based on the methodology developed by Zonensein (2007).

For the Income Indicator (Figure 2), the darker tones indicate the census sectors with homes that have a higher monthly average income, and they correspond the high class neighborhoods in the study area. It is notable the discrepancy between high class neighborhoods and others with very low income (some of the cities' poorer regions are in this zone). It is also notable that, in this construction proposed by Zonensein (2007), the biggest vulnerability refers to the largest income: the concern is with the loss of assets and damage to infrastructure and does not intend to reflect social weakness.

The sectors indicated with the largest percentage of inadequate sanitation (Figure 3 ) are the sectors right by the edge of the stream and that dispose of their effluent in it, and the sectors that do not have public collection and use septic cesspools.

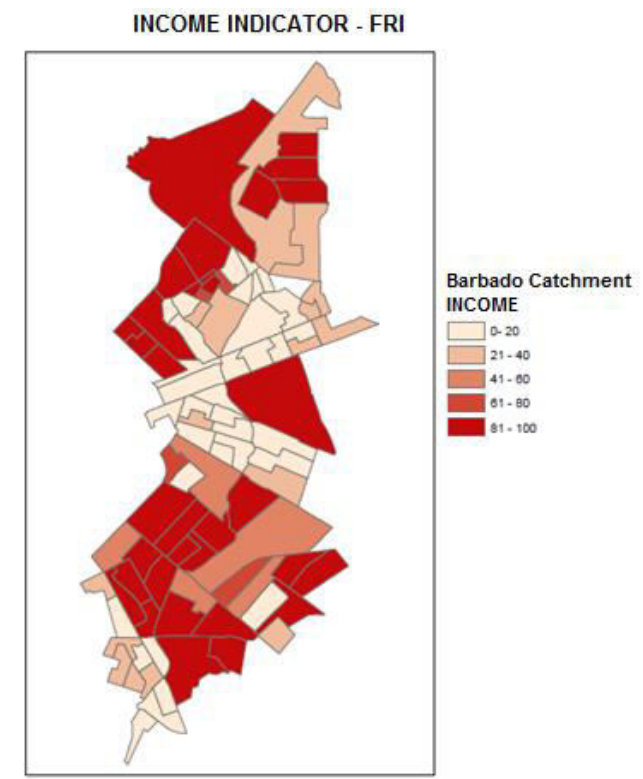

Figure 2: Consequences SubIndex - Income Indicator
INADEQUATE SANITATION INDICATOR - FRI

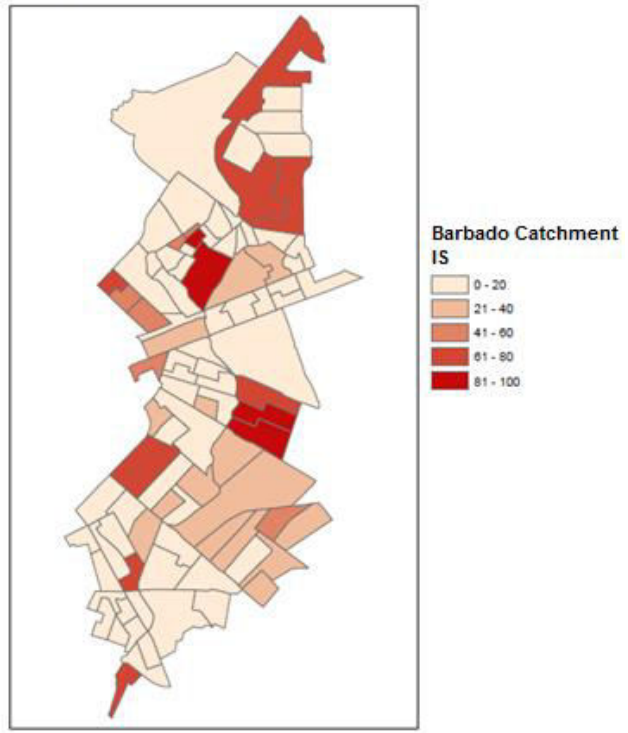

Figure 3: Consequences SubIndex - Inadequate Sanitation Indicator

According to Figure 4, the largest part of the Barbado cacthment has a lower density of homes (represented in its majority of horizontal houses and residential neighborhoods). The biggest numbers found are concentrated on the Terra Nova neighborhood (a fully verticalized neighborhood), and around the border of the main structural roads in the city. Due to the road tiering in Cuiaba, the Barbado catchment is cut by roads that link the city in the North-South and Center-East ways, in a form that most of the census sectors were classified as highly vulnerable (Figure 5).

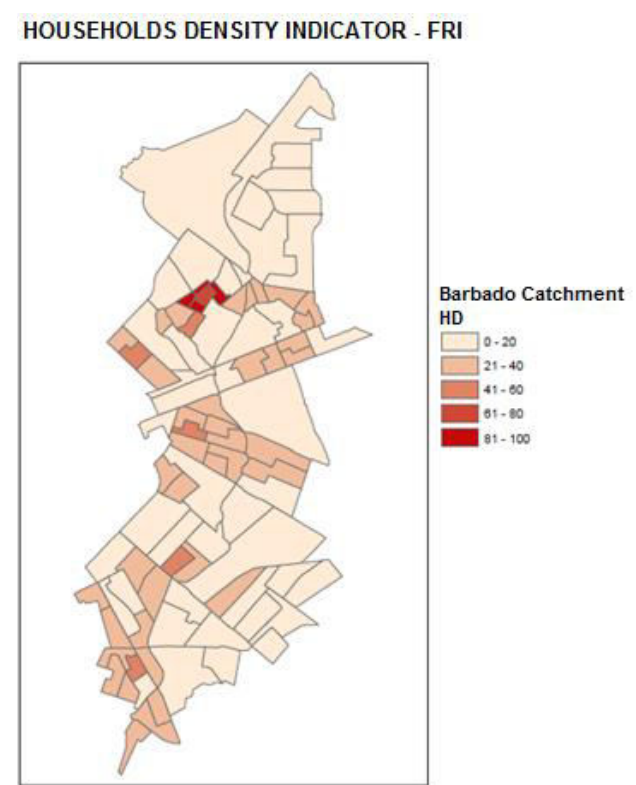

Figure 4: Consequences SubIndex - Households Density Indicator 


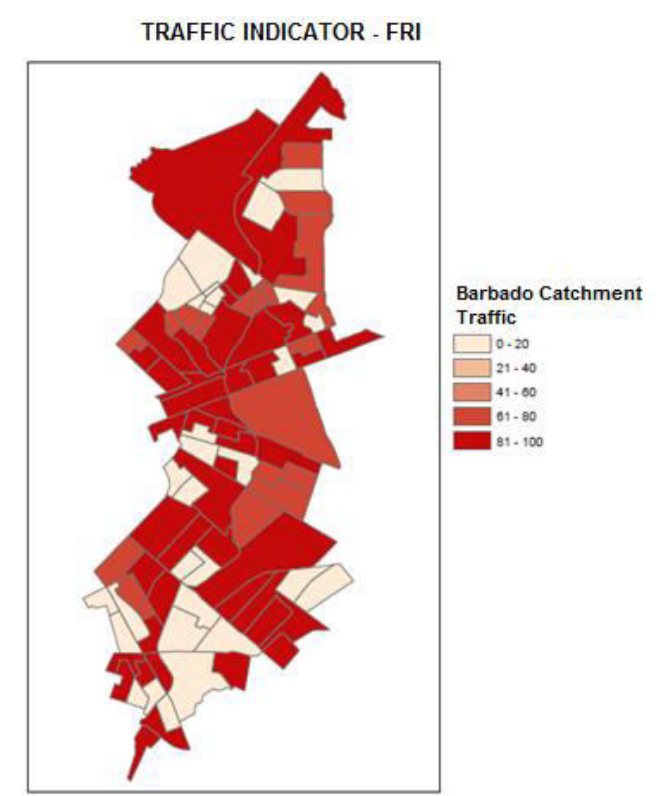

Figure 5: Consequences SubIndex - Traffic Indicator

To determine the Consequences index (the one that reflects the vulnerability), it is necessary to define each indicator's weight, those being $\mathrm{I}_{\mathrm{I}}=0.2, \mathrm{I}_{\mathrm{IS}}=0.1, \mathrm{I}_{\mathrm{HD}}=$ $0.4, \mathrm{I}_{\mathrm{T}}=0.3$. The weight definition was given to seek privilege the most affected infrastructure systems when facing a flood: the homes (its residents and assets) as well as the traffic system (which is greatly impacted). Remembering that those are liable of being adapted as needed. Figure 6 represents this results. Since this subindex intends to measure the vulnerability of the urban system infrastructure, as a way to quantify the risks to witch said system is exposed to, it's noticeable that to the Barbado catchment that most of its area has average to high vulnerability in its traffic system, sanitation and homes. Information that when combined with the physical specificitiesfrom the overflow, tells the dimension of risks produced by a flood on that place.

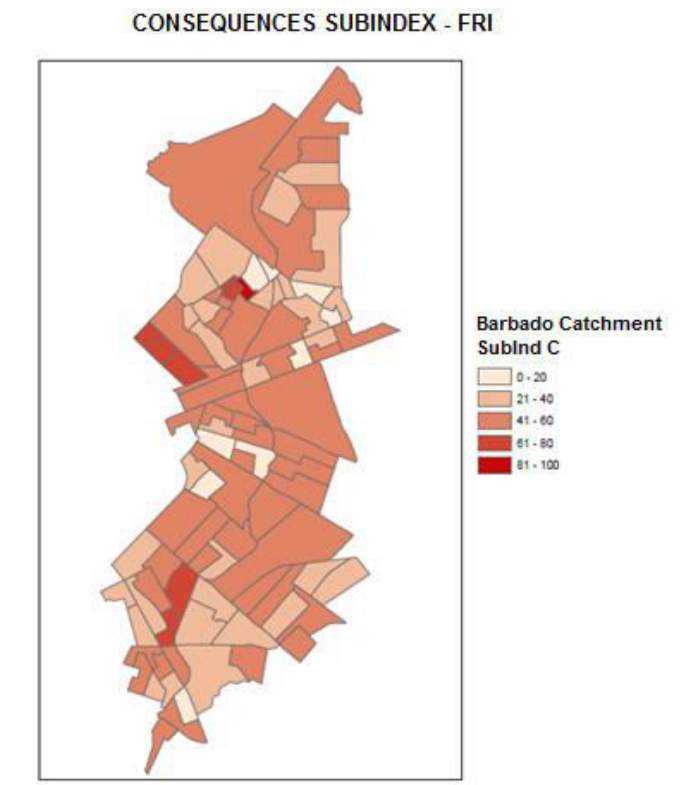

Figure 6: Flood Risk Index - Consequences SubIndex
SVI

Two alterations were made to the social vulnerability index proposed by Koks et al (2014): the number of non-european migrants was excluded, and an approximation to the propriety construction year (such information is not available through the IBGE database), and so $t$ was possible to approximate to the valor due to neighborhood foundation year to each the census sector belongs. Seeking to valuate the influence of each parameter to the index construction in a more precise manner, the following weights were adopted: $I_{\text {income }}=0.4$, $\mathrm{I}_{<1 \text { yearsofage }}=0.2, \mathrm{I}_{>65 \text { yearsofage }}=0.2, \mathrm{I}_{\text {oneparentfamilies }}=0.1$, $I_{\text {constructionyear }}=0.1$. Those weights were chosen due to the characteristics that have the biggest influence to the increase of social vulnerability on the original index (Koks et al, 1024), those being the income and the age. The response to that situation is presented on Figure 7.

It is noticeable that neighborhoods with largest purchasing power tend to be less vulnerable, and neighborhoods with the largest number with people younger than 14 years of age are more vulnerable. It is also notable that more than half of the population is in areas of average to high social vulnerability, especially in sectors around the border of the stream, and those with low income, where the income and age rate factors are combined. With the adaptations and weight distribution, the index appear to have accomplished the goal of indicating the main social vulnerabilities.

\section{SOCIAL VULNERABILITY INDEX}

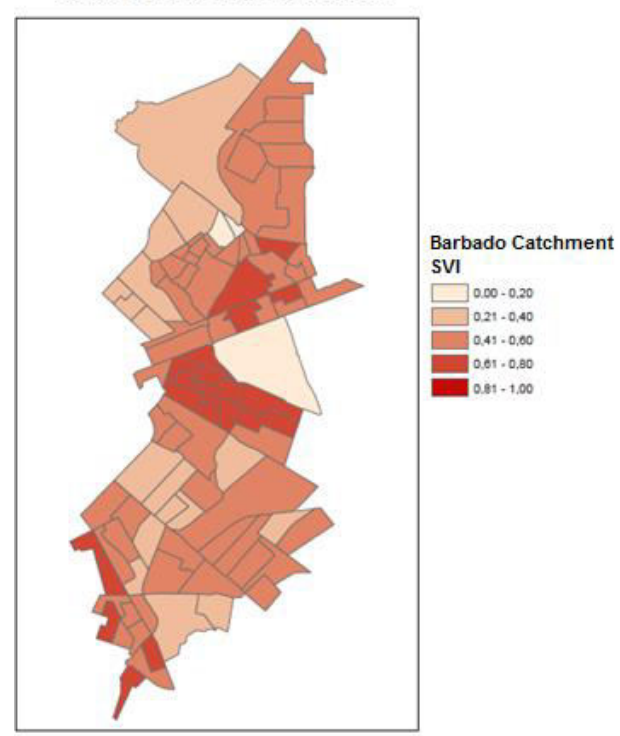

Figure 7: Social Vulnerability Index

\section{SEnVI}

This index is composed by two subindexes responsiveness, and structural exposure, both calculated separately to make up the final index.

For the structural exposure, the indicators are: construction type, illumination, water supply, sewage, garbage collection, home ownership and its characteristics (number of rooms) that compose the description of the built environment. For this study, it was not possible to include variables such as: construction type and number of rooms. Saito (2011) 
worked with a HAP technique to determine the weight of each indicators variable, respecting the numbers proposed. For the final composition of the subindex, the determination for each indicator's weight is as follows: $\mathrm{I}_{\text {water }}=0.25, \mathrm{I}_{\text {sewage }}=0.25, \mathrm{I}_{\text {gargabe }}=0.25, \mathrm{I}_{\text {homeownership }}=$ $0.15, \mathrm{I}_{\text {illumination }}=0.1$. The results are expressed Figure 8 .

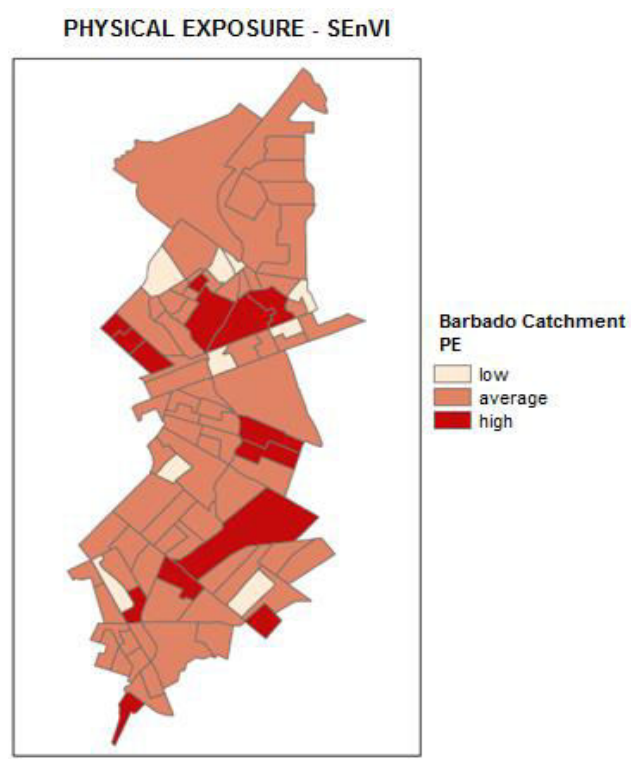

Figure 8: SEnVI - Physical Exposure

It is noticeable that half of the census sectors have an average structural exposure (ranks obtained based on the average and standard deviation of the obtained values, with average value: 17,43 and deviation: 13,00). Such values were rounded up, due to high rate of rented houses with inadequate sewage and garbage collection, and water supply from wells in the neighborhoods classified as low income, and also for the elevated number of residences with sanitation by septic cesspools.

The population's responsiveness when facing threats is evaluated through the following indicators: age, education, marital status, race, job market situation, number of residents and residence time. This subindex also needed alterations, excluding some variables: job market situation and residence time. As seen on Figure 9, the following weights were applied: $\mathrm{I}_{\text {income }}=0.4, \mathrm{I}_{\text {education }}$ $=0.3, \mathrm{I}_{\text {maritalstatus }}=0.1, \mathrm{I}_{\text {numberofresidents }}=0.1, \mathrm{I}_{\text {race }} 0.1$.

The responsiveness evaluates the population's social conditions and how it can respond to a flood event, such response is influenced by income, age and education of the population. The highest responsiveness values were obtained on the sectors with the highest income, lower number of residents, higher education rate and largest number of residents between the ages of 18 and 60 years old. The sectors with lowest income, higher illiterate rate and largest number of residents have the worst variable values.

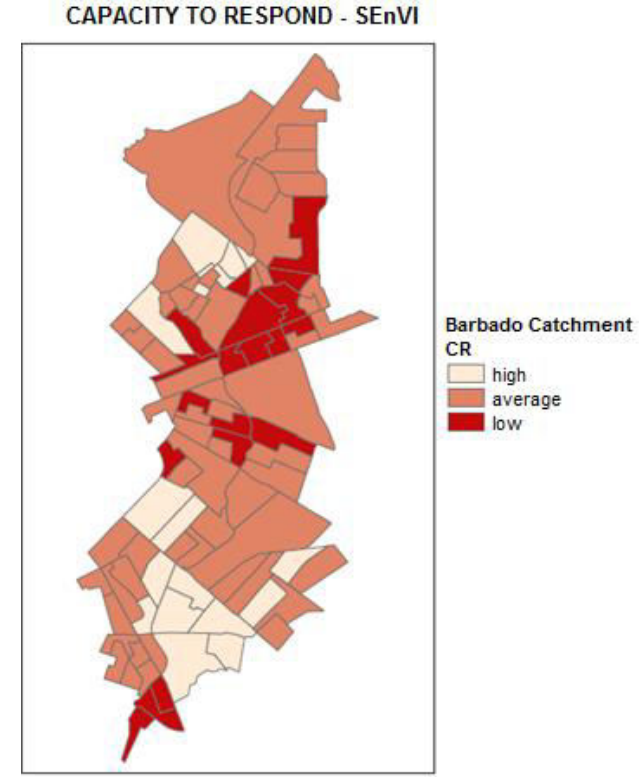

Figure 9: SEnVI - Capacity to Respond

For the SEnVI calculation, Saito (2011) found a better correlation of structural exposure with the socioenvironmental vulnerability, and then it is recommended the adoption of a higher value of weight to the structural exposure component, and the responsiveness component is worked as a fine adjustment in the index attainment. For Cuiabá, the weight determination was given according to this recommendation, the values being: structural exposure indicator $=0.75$ and responsiveness indicator $=0.25$. Image 10 shows the results of the application of SEnVI to the study area.

\section{SOCIO-ENVIRONMENTAL VULNERABILITY INDEX}

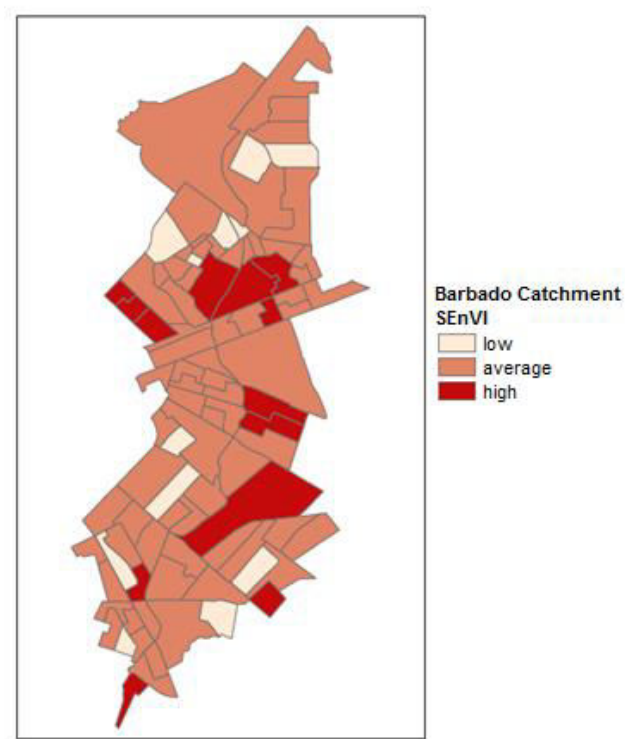

Figure 10: Socio-Environmental Vulnerability Index

It is important to highlight that Saito (2011) did not actually work with the natural environment, but with a built environment and the vectors of its degradation (such as lack of sanitation, for example).

From the combination of the components: structural exposure and responsiveness to determine the Barbado 
stream catchment urban system socio-environmental vulnerability, it was possible to reach a result that more than half of its census sectors are classified as having an average socio-environmental vulnerability (average value: 28,47 and standard deviation: 10,17 ), outcome that has a strong relation to the structural exposure found in the watershed, because even if the population has a good responsiveness, if the structural exposure is from average to elevated, the vulnerability tends to have a higher value.

\section{SEcVI}

For the calculation execution, it is necessary to determine the vulnerability range for each studied indicator (vulnerability ranging from 1 to 5). This determination followed the patterns exposed on the original study, with small alterations being made to fit the national reality. Such ranges are described next:

\section{Population density}

$1-\mathrm{PD}<50$ inhab $/ \mathrm{Km}^{2}$

2 - PD entre 50 e 100 inhab/ $\mathrm{Km}^{2}$

3 - PD entre 100 e 250 inhab $/ \mathrm{Km}^{2}$

$4-\mathrm{PD}$ entre 250 e 500 inhab $/ \mathrm{Km}^{2}$

$5-\mathrm{PD}>500 \mathrm{inhab} / \mathrm{Km}^{2}$

\section{Education}

Ps: NPL - number of literate people

$1-\mathrm{NPL}>90 \%$ Number of people older than 18 years of age

2 - NPL from $80 \%$ e $90 \%$ Number of people older than 18 years of age

3 - NPL from $70 \%$ e $80 \%$ Number of people older than 18 years of age

4 - NPL from $60 \%$ e $70 \%$ Number of people older than 18 years of age

$5-\mathrm{NPL}<60 \%$ Number of people older than 18 years of age

\section{Age distribution}

1 - Less than $20 \%$ of the population from 0 to 5 years of age or older than 65 years of age

2 - From $20 \%$ to $30 \%$ of the population from 0 to 5 years of age or older than 65 years of age

3 - From $30 \%$ to $40 \%$ of the population from 0 to 5 years of age or older than 65 years of age

4 - From $40 \%$ to $50 \%$ of the population from 0 to 5 years of age or older than 65 years of age

5 - More than $50 \%$ of the population from 0 to 5 years of age or older than 65 years of age

\section{Household income}

PS: Homes with monthly household income per person (MW minimum wage)

1 - Largest \% household income $>10 \mathrm{MW}$

2 - Largest \% household income from 5 to $10 \mathrm{MW}$

3 - Largest \% household income from 3 to $5 \mathrm{MW}$

4 - Largest \% household income from 1 to $3 \mathrm{MW}$

5 - Largest $\%$ household income $<1 \mathrm{MW}$

\section{People responsible for the income}

1 - More than $90 \%$ of the people responsible present income

2 - From $80 \%$ to $90 \%$ of the people responsible present income

3 - From $70 \%$ to $80 \%$ of the people responsible present income

4 - From $60 \%$ to $70 \%$ of the people responsible present income

5 - Less than $60 \%$ of the people responsible present income

\section{Home type}

1 - Most of the homes consist of apartments
2 - There is a similar proportion of apartments and village houses

3 - Most of the homes consist of village houses

4 - Most of the homes consist of houses

5 - Virtually all of the homes consist of houses

The indicators were classified according tot he ranges proposed above. For the construction of the combined vulnerability index, it was necessary to use the weighing of importance proposed on the original article, in the way that the indicators were distributed like so: lowest influence (weight 1) - home, population density; average influence (weight 2) - age, income, people responsable for the income; highest influence (weight 3) home type.

After the equation proposed was applied to the aggregation of the socioeconomic vulnerability index, that index was spacialized on the Barbado stream watershed, and Figure 11 presents those results.

The index proposes the variation of vulnerability in five ranges - low, low-average, average, average-high, high. With the map analysis, it is noticed that a large part of the watershed has a standard of average to averagehigh socioeconomic vulnerability, such value highly represented by home type, household income and elevated population density. An interesting information is that the number of people responsible for the income in most of the census sectors is elevated, however that income is low, which has the potential to round up the index to higher ranges.

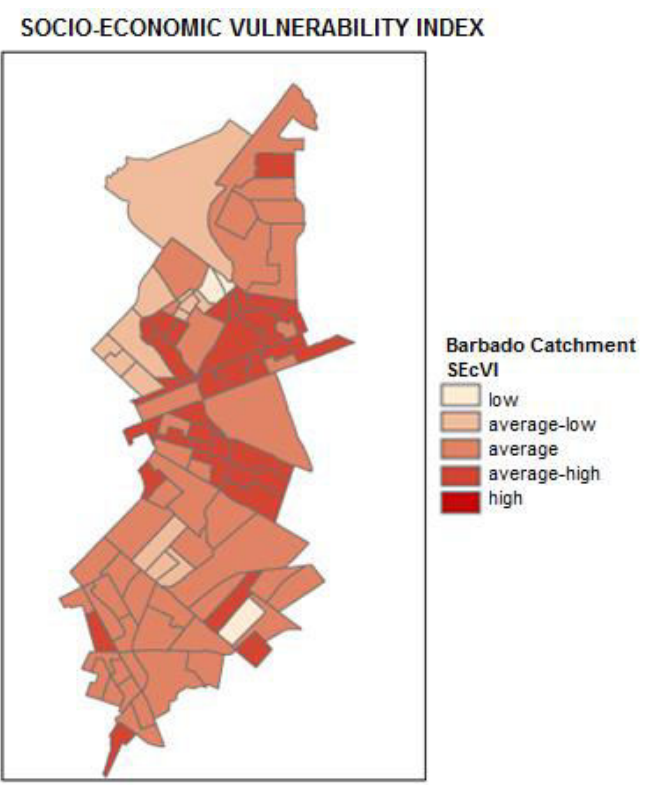

Figure 11: Socio-Economic Vulnerability Index

It is considered that evaluating the vulnerabilities is an indispensable part when managing flood risks, the results being a plausible database to the city's urban management. The maps produced from the analysis of the different ways of vulnerability can be used in several situations. Next, some situations are identified:

-Planning and controlling the occupation and soil usage; 
-Realizing and directing preventive actions, both structural and non-structural;

-Realizing Civil Defense preparation actions in the scope of most vulnerable regions;

-Performing distant monitoring (from monitoring agencies);

-Planning reconstruction actions (municipal and state public power);

- Forming a database for flood risk mitigation financing (being either public or private financing).

\section{Conclusions}

The analysis of social, environmental, economic and structural vulnerabilities is an important tool in the steps for planning and control of use and ocupation of the soil, because it is possible to show the already occupied areas, which are the critical regions from the social point of view, economic and/or environmental, enabling the public power to direct efforts to actions accomplished in those areas.

Agencies for environmental monitoring can perform a remote monitoring based on the knowledge of the vulnerability on the sudied area, which can also instigate the posterior alert emission since, from the confirmation of a dangerous event knowing the characteristics of the vulnerability of the exposed ppopulation (number of homes, income, environmental characteristics), it is possible to send out directed alerts. Civil Defense can use the information from the regions with the vulnerability monitored to realize preparation and response actions to flood events, and also reconstruction actions post-events, since the local specificities are known.

As continuity to this study, is recommended the junction of urban vulnerability date to a mapping of the water levels from urban flood simulation studies to a better understanding of the flood risk management process; it's also suggested the proposition of a composed index that seeks to assemble the dispersed information from the evaluated indexes, with the goal to provide a unique tool to be used in the planning and control of the urban soil usage process. Lastly, the tooling outline developed with the continuity of the study must be integrated to the urban planning.

\section{References}

1. BIRKMANN, J. (2005). Danger need not spell disaster but how vulnerable are we? United Nations University, $\mathrm{N}^{\mathrm{o}} 1$.

2. CARDONA O. D. et al. (2005). System of indicators for disaster risk management: main technical report. Manizales - Washington: Instituto de Estudios Ambientales Universidad Nacional de Colombia/InterAmerican Development Bank.
3. CARVALHO, M. A. C. C. (2013). Hydrological situation of the work of implementation and duplication of Barbado Park Avenue using the SWMM in Cuiabá MT. Study Completion of course (graduation), Federal University of Mato Grosso, Cuiabá. (in Portuguese)

4. CASTRO, C. B. et al. (2005). Environmental risks and Geography - conceptualizations, approaches and scales. Yearbook of the Institute of Geosciences, UFRJ. (in Portuguese)

5. CUIABA. (2007). Law No. 150/2007: establishes the Master Plan. (in Portuguese)

6. CUIABA. (2009). Institute of Planning and Urban Development. Socio-economic Profile of Cuiabá. Central text. (in Portuguese)

7. CUIABA. (2015). Law No. 389/2015: establishes the Law of Use, Occupation and Land Urbanization. (in Portuguese)

8. CUTTER S. L. (1996). Vulnerability to environmental hazards. Progress in Human Geography, v.20, no 4.

9. CUTTER, S. L. et al. (2000). Revealing the vulnerability of people and places: a case study of Georgetown County, South Carolina. Ann. Assoc. Am.

10. EIDSVIG, U. M. K. et al. (2014). Assessment of socioeconomic vulnerability to landslides using an indicator-based approach: methodology and case studies. Bulletin of Engineering Geology and the Environment, Springer.

11. FARIA, N. O. (2013). Study of waterproofing, monitoring, modeling and simulation scenarios for the Barbado catchment- Cuiabá/MT. Masters dissertation. Federal University of São Carlos, São Carlos/SP. (in Portuguese)

12. IBGE. (2010). Population Census. Brazil. (in Portuguese)

13. KOKS, E. E. et. al. (2014). Combining hazard, exposure and social vulnerability to provide lessons for flood risk management. Environmental, Science \& Policy, Elsevier.

14. O'RIORDAN, T. (2002). Precautionary Principle, Encyclodia of Global Environmental Change, vol. 4. Chichester, UK: John Wiley.

15. ROTERBATH, A. V. P. et al. (2013). Evaluation of environmental impacts arising from the disposal of solid waste on the banks of the stream Barbado, Cuiabá - MT. 14th Brazilian Congress of Engineering and Environmental Geology. (in Portuguese)

16. SAITO, S. M. (2011). Environmental dimension in the management of risks of precarious settlements of massive Morro da Cruz, Florianópolis - SC. Doctoral thesis. Federal University of Santa Catarina, Florianópolis/SC. (in Portuguese)

17. SAATY, T. L. (2005). Theory and applications of the Analytic Network Process: Decision making with benefits, opportunities, costs, and risks. Pittsburgh, USA: RWS.

18. SEPLAN/MT. (2009). Zoning Socio-economicecological of Mato Grosso. Climatogy- climatological data. (in Portuguese)

19. UNDP. (2004). Reducing disaster risk: a challenge for development, a global report. UNDP. Bureau for Crisis Prevention and Recovery. New York: UNDP. 
20. VENTURA, R. M. G. (2011). Environmental and hydrological characterization of Barbado stream catchment in Cuiaba - MT. Masters dissertation. Federal University of Mato Grosso, Cuiabá. (in Portuguese)

21. WORLD BANK. (2012). Cities and Flooding. A Guide to Integrated Urban Flood Risk Management for the 21 st Century. Washington, DC.

22. WU, S. Y. et al. (2002). Vulnerability of coastal communities to sea level rise: a case study of Cape May county, New Jersey, USA. Clim. Res.

23. ZONENSEIN, J. (2007). Full Risk Index as flood management tool. Master's Thesis, Civil Engineering, Federal University of Rio de Janeiro/COPPE. Rio de Janeiro. (in Portuguese)

24. ZORZO, A. P. (2015). Study of the flooding of conditions on Fernando Correa da Costa Avenue, Cuiabá/MT. Study Completion of course (graduation). Federal University of Mato Grosso, Cuiabá. (in Portuguese) 